\title{
APPLICATION OF HIGH-POWER LASERS TO EQUATION-OF-STATE RESEARCH AT ULTRAHIGH PRESSURES
}

R. J. Trainor, H. C. Graboske,

K. S. Long, and J. W. Shaner

March 1, 1978

Work performed under the auspices of the U.S. Department of

Energy by the UCLLL under contract number W-7405-ENG-48

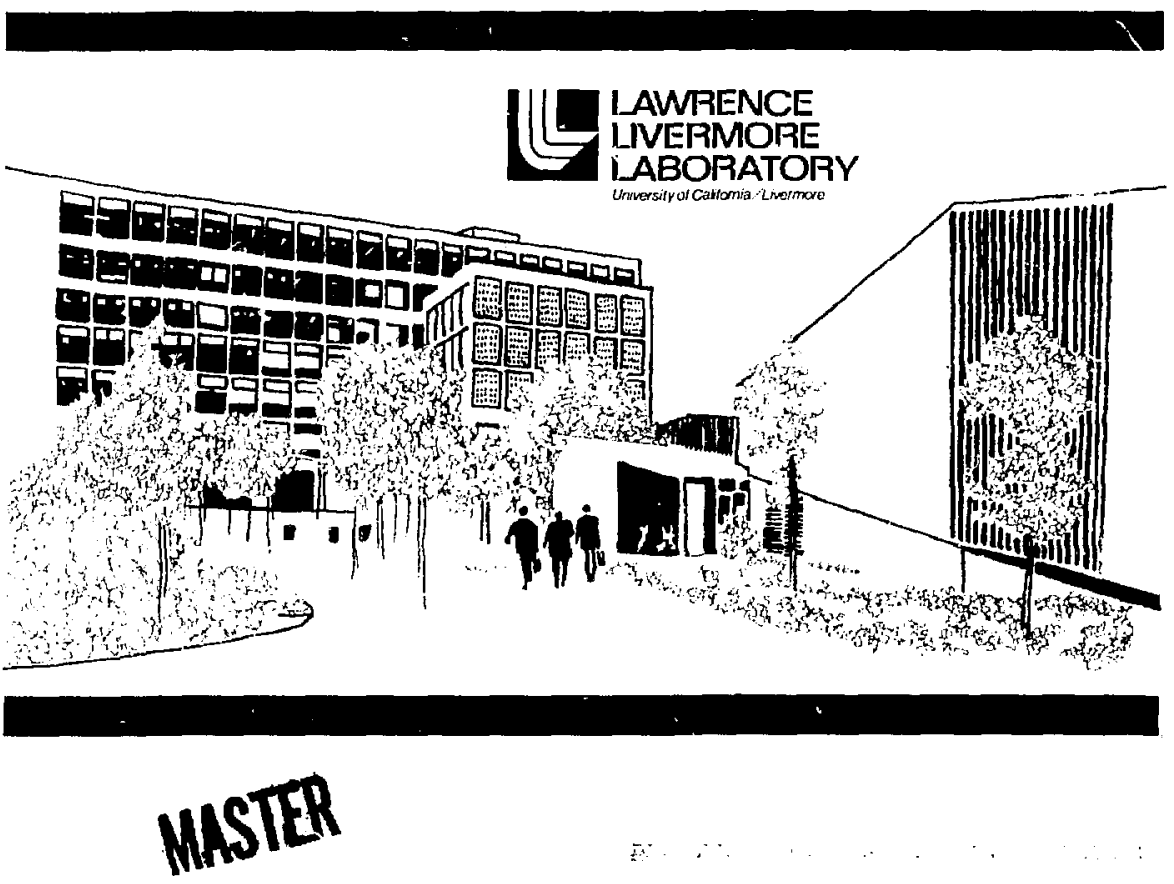




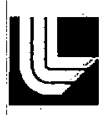

\title{
I_AWRENCE IJVERMORE I_ABORATORY
}

University of Cahfornia Livermore, Californias 94550

\author{
UCRL. 52562
}

\section{APPLICATION OF HIGH-POWER LASERS TO EQUATION-OF-STATE RESEARCH AT ULTRAHIGH PRESSURES}

R. J. Trainor, H. C. Graboske,

K. S. Long, and J. W. Shaner

MS. date: March 1, 1978

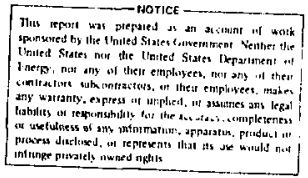




\section{CONTENTS}

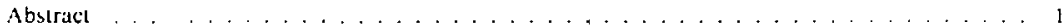

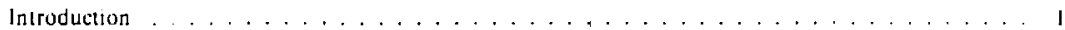

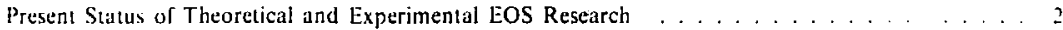

Shock Pressurc tchievable with LLL High-Power Lasers . . . . . . . . . . . . . . . . 4

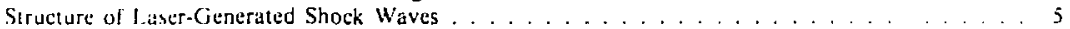

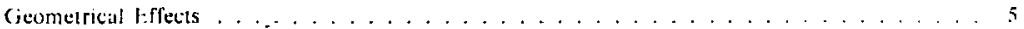

t: rects of Spatial Variation in Laser Intensity . . . . . . . . . . . . . . . . . . 5

Absorption Mechanisms that Depend on Angle of Incidence . . . . . . . . . . . . 5

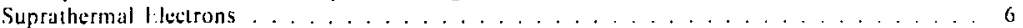

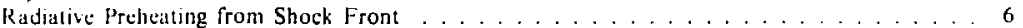

Thermoclectric Transport across Shock Front . . . . . . . . . . . . . . . . G

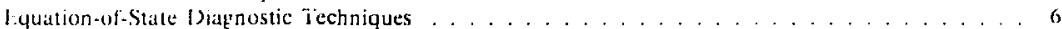

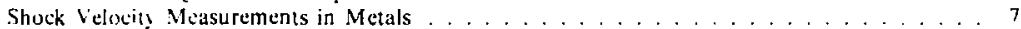

Shock Velocity Measurements in Transparent Solids . . . . . . . . . . . . . . . . 8

Particle velocils Measurement . . . . . . . . . . . . . . . . . . . 9

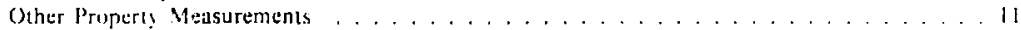

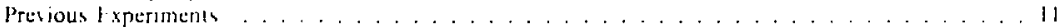

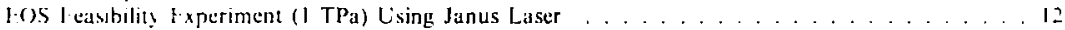

Argun toS 1 xperment Desigred to Reach $2 \mathrm{TPa} \ldots \ldots \ldots \ldots \ldots$

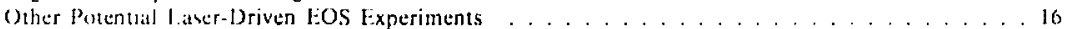

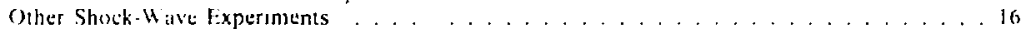

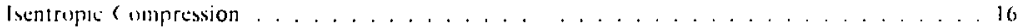

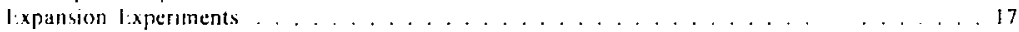

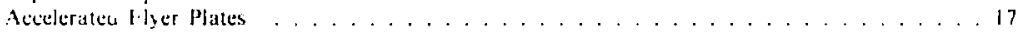

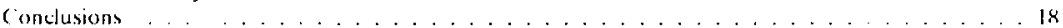

Appendix \. Temperature Measurements in Laser-Shocked Materials . . . . . . . . . . . 20

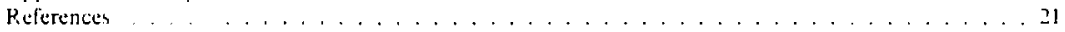




\title{
APPLICATION OF HIGH-POWER LASERS TO EQUATION-OF-STATE RESEARCH AT ULTRAHIGH PRESSURES
}

\begin{abstract}
The application of high-power pulsed lasers to ultrahigh pressure equation-ofstate (FOS) experiments is discussed. It is shown that pressures along the principal Hugoniot between 1 and $10 \mathrm{TPa}$ can be produced with existing lasers used for inertialconfinement fusion research. The relevance of measurements in this pressure regime to improving our understanding of condensed matter physics is also discussed. New experimental techniques as weil as potential experimental problems are described, and EOS experiments on the Janus and Argus laser systems are proposed.
\end{abstract}

\section{INTRODUCTION}

The capibility of high-power lasers to generate ultrahigh pressure shock waves has bеeл recognized for many years. When a laser pulse is focused onto the surface of a solid target, a partially absorbing plasnta is rapidly formed. Laser energy is absorbed in the low-density regions of this expanding plasmia (electron density $<10^{21} \mathrm{~cm}^{-3}$ for $\mathrm{Nd}$-glass-laser irradiation) and transported by electronic thermal conduction into the solid target. Material is blown off of the target into the lower density plasma, and this ablation drives a shock wave into the target ahead of the ablating surface. As irradiation continues, the critical surface, where the local plasma frequency equals the laser frequency, moves away frum the initial target surface, while the ablation front moves into the target at a velocity less than the shock velocity. Unon termination of the laser pulse, pressure drops rapidly at the ablation surface, aud a rarefaction wave propagates into the target, evenlually overtaking and altenuating the shock.

In the early studies by Kidder ${ }^{1}$ and others, ${ }^{2}$ simpie but useful relationships were derived relating the shock pressure, $P_{1}$ to the absorbed laser intensity, I." Assuming a one-dimensional problem in which the blow-off velocity is subsonic and the plasma is an ideal gas with heat capacity ratio, $\gamma$, equal to $5 / 3$, one can write:

* Jor a review of the laser-matter interaction problem up to 1975, see Rol. 3.

$$
\left.P=(0.055)(A / Z)^{1: 3}\right]^{2 ; 3}
$$

where $P$ is in TPa (1 TPa $=10$ Mbar), 1 is in $10^{12}$ $W / \mathrm{cm}^{2}, A$ is the ulomic weight of the ions, and $Z$ is the degree of jonization. Energy absorbed in ioniring the atoms has been ignored in this formulation.

Equation (1) implies that the shock pressures produced by laser irradiation atre relatively insensitive to material density, as opposed to pressures generated by conventional plate-impact or impedance-matching lechniques. More importantly, Eq. (I) predicts that a laser producing an intensity of $10^{12} \mathrm{~W} / \mathrm{cm}^{2}$ can generate pressures in the 100-GPa range. We will show that with the very high-power lasers at J.l.l., it is reasonable to consider experiments up to the 10-TPa range.

The proper assessment of the properties of laser-generated shocks and the design of experiments, of coursc. require a much more detailed understanding than Eq. (1) can provide. For example. the absorption of laser light may be highly dependent on untensity and material, and may be affected by the temporal structure of the pulse as we!!. Preheat effects due to high-energy photons and electrons produced during the laser-light absorption process play a strong role in high-intensity laser compressions and must be understood. Finally, the temporal nature of the pulse and the evolution of the thermal properties between the critical surface and ablation front strongly regulate the lifetime and the spatial distribution of the shock wave. To more 
properly understand these phenomena, a sophisticated hydro-code with radiation and charged particle transport, such as LASNEX, ${ }^{4}$ must be used.

In this report we discuss the potential application of the high-power glass-laser systems at LLL. to ultrahigh pressure equation-of-state (EOS) research. The extreme energy densities attainable with the Janus, Argus, and Shiva lasers are well known in the field of laser-induced-fusion research. We shall show that these lasers also offer the possihility of performing accurate equation-of-state experiments at shock pressures in the 0.1-to- 10-TPa range, where present theoretical models are least reliable and experimental data are extremely limited.

The first parl of this report surveys the present status of theoretical toS for materials at exireme pressures and temperatures. The remainder of the report is an assessment of the feasibility of EOS experiments using the LLLI. laser systems. We shall address both specific experiments. which may be implemented immediately using presently developed facilities and diagnostics, and more general concepts, which may be developed over the next decade.

\section{PRESENT STATUS OF THEORETICAL AND EXPERIMENTAL EOS RESEARCH}

High energy-densily conditions occur in many situations in astrophysics, geophysies, and manmade laser-driven compressions. A sludy of the phenomena associated with these conditions requires the knowledge of the properties, such as the equilibrium state and transport behavior, of many materials over cxtreme ranges of temperature and densily.

Theoretical approaches to the necessary equilibrium thermodynamics are of three general types. First. fundamental theories, based on our understanding of the underlying physics, attempt to be rigorous and complete, but they are correct only in some asymptotic limits of temperature and density. Examples are the Saha ionization equilibrium theory, valid at low densities, and Coulomb fluid theory valid at high densities. Second, approximate theoretical models are simplifications of firstprinciples theories, where known complications are either neglected or approximated. An example of a contemporary approximate theory is the Augmented-Plane-Wave (APW) model for electronic band structure of solids. A third approach involves phenomenological or totally empirical models, in which parameters are adjusted to agree with experimental data. A global EOS model may require all three approaches in various temperaturedensity regions, together with procedures for combining them in a thermodynamically consistent way.

The difficulty of accurate thermodynamic characterization of a material may be demonstrated by reference to the schematic diagram shown in Fig. 1. Here the useful range of several theoretical models has been indicated. Important factors unrepresented in this illustration include the complex- ities of atomic number-dependence and molecular structures. The eight theoretical regions shown can be divided into three classes as follows:

Class I. Theoretically precise

- Ideal and weakly coupled plasma

- Saha ionication equilibrium

- High density Coulomb Iuid

Class 2. Theoretically approximate, ranging from accurale to inaccurate depending on $T, p$

- Dense partially ionized plasma

- Multiphase and neutral fluid

- Condensed mitter

Class 3. Theoretically intractable at present

- Strong pressure ionization

- Hot, charged, dense plasma-liquid.

The theorics listed as precise are supported by laboratory or astronomical experimental data in the appropriate $T_{,}$, regions. The approximate theorits of the second class generally appproach the rigorously correct theories in their appropriate $T, p$ limit. For example, the dense partial ionization model has the Saha ionization equilibrium as its low $p$ and high $\mathrm{T}$ asymptote. To some degree there theories huve experimental support. The intractable regimes represent the thermodynamic region where present modeling is least reliable.

The range of dati from contemporary experimental techniques is also indicated in Fig. 1. These techniques include:

- Static compression, using high-pressure presses, sucb is diamond anvils, for netasurements on the isotherm up to $\sim 0.1$ TPa. 5.6

- Explosive and gas-gun-generated shockwave compression ror measurements on or near the principal Hugoniot at pressures up to $\sim 0.5 \mathrm{TPa}$. 


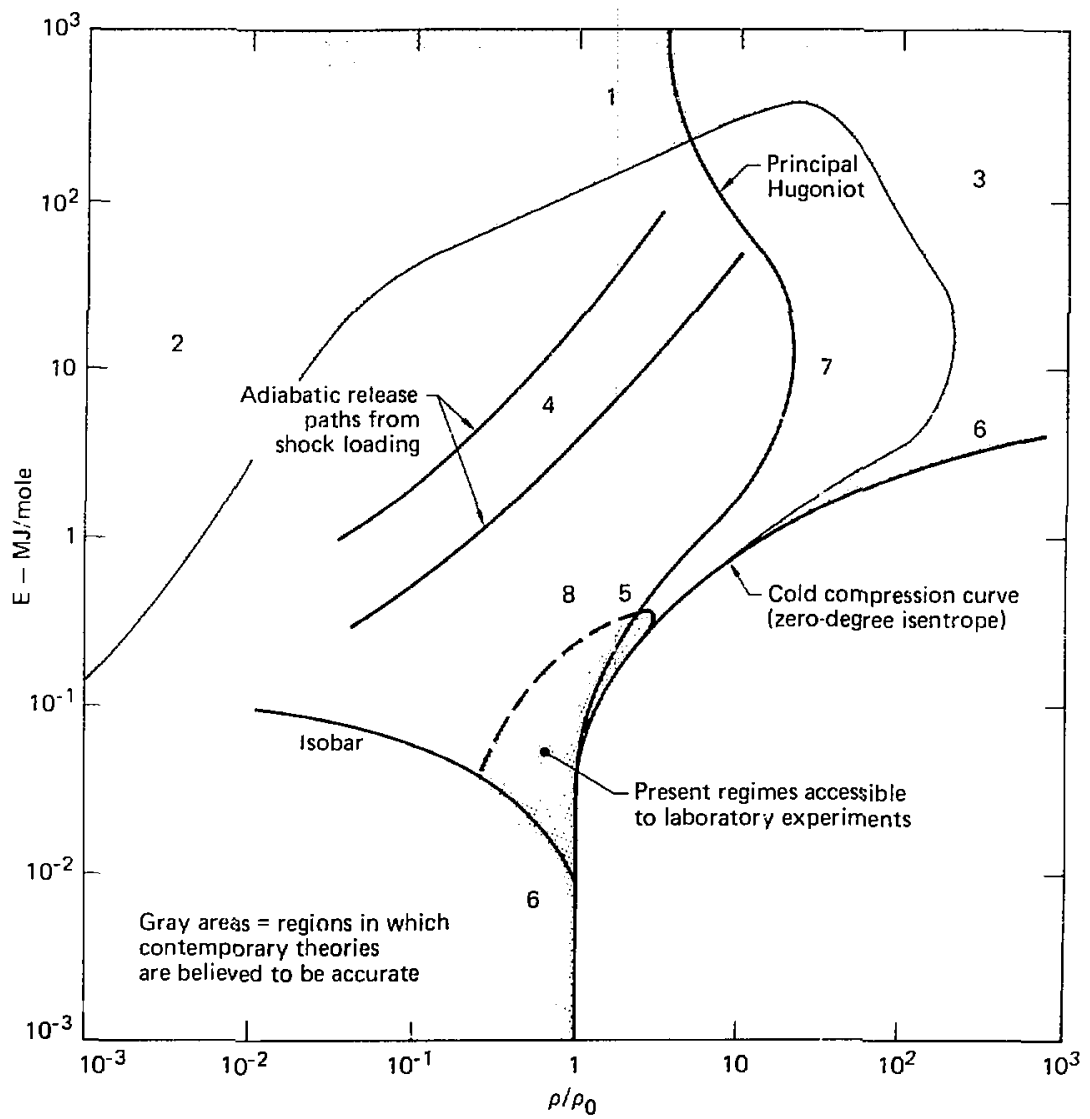

Fig. 1. Schematic diakram of energy-density plane of EOS surface for fictitious but realistit material. The eight follow ing ure the theotelicul

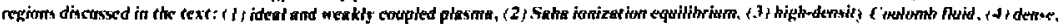

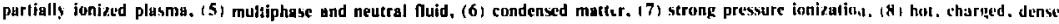
plasma-liguid.

- 1sobaric expunsion ${ }^{7}$ for measurements in expanded hot liquid metals at temperatures up to $\sim 1$ eV.

- Magnetic hux implosion for measurements along the isentrope to pressures oi 0.5 to I TPa. ${ }^{8}$

Hugoniot measurements have also been made in the 1-to-5-TPa range by $\mathrm{Al}$ 'tshuler $e t$ al. ${ }^{9}$ in the Soviet Union, and by Rugan et al. at LASL, ${ }^{10}$ both using a nuclear explosion as the driving source. Recent revisions in the standards used in the Soviet exfariments have changed the data by as much ats $50 \% .11$ Because of their questionable acturacy, these data are not included in Fig. I. The dati point by Ragan et al. is not included hecause their experimental technique was applicable only to molybdenum. 
We see that the range of vitidity of present theoretical models forms one outer boundary about a portion of the EOS space shown in fig. 1, whered 5 inother boundary is formed by the range of present accurate experiments. Intermediate to these regimes lies a large and poorly characterized region. This is the region where one must presently resort to statistical atom theories (Thomas-fermi) or interpolation techniques.

The purpose of the experiments proposiof in the following sections is 10 bridge this iarge gap be- tween experimentally and theoretically understood portions of the EOS surface. The emphassis in this report will be on Hugoniot measurements, becaus. methods for studsing the Hugoriot at ultrahigh presisures appear most soundly developed at present. It is also important to realize that, because the Hugoniot traverses at central portion of the loS space shown in Fig. 1. accurate data along this thermodynamic path can previje important tie points for interpolations betwcen the varieus theoretically understood regions.

\section{SHOCK PRESSURE ACHIEVABLE WITH LLL HIGH-POWER LASERS}

The pursuil of fusion by inertial conlinement has led to the development at J.I.L of the world's most pouerful lasers. He will be diccussing four L.1. laser facilities ${ }^{12}$; euch in its time has been, is, or will be the world's most powerful. The smallest laser is Janus. constructed in 1974 and capable of delivering a maximum of ahout $200 \mathrm{GW}$ of power in Gaussian pulses as long as $300 \mathrm{ps}$ I-WHM in each of its (wo arms. Srgus, conpleted in 1976, san deliver up to several terrawatts on larget in pulses potentially as long as several nanoseconds. Shiva, which began operation in December 1977, has twenty beams, bundled into two branches, and is expected to produce ahout 10-15 TW in tach hranch. Shivi Nova, seheduled for the early $1980^{\circ} \mathrm{s}$, will produce $100 \mathrm{TW}$ in each of two branches.

We have used the LASNEX code ${ }^{4}$ to study the irradiation of 1-mm-diam disks of solid $\mathrm{J}_{2}$, L.H. $\mathrm{Fe}$, and $\mathrm{U}$ by the aforementioned lasers. The maximum pressures achievable in these materials are summarized in Fig. 2. The pulse characteristics are listed in the figure caption. Figure 2 also shows the maximum shock pressures possible in these materials using conventional laboratory techniques. 11 is seen that even in a Janus EOS experiment. pressures could bc produced that would exceed those possible by atly other present laboratory technique. With the more powerful lasers, interesting regimes of present theoretical uncertainty could be experimentally addressed for the first time.

As exciting as the prospect of doing experiments in a presently inaccessible regime of LOS space might be, the Foregoing discussion remains little more than a curiosity unless uccurate diagnostic tecinniques can be developed. $\mathrm{lt}$ is easy to appreciate that the diagnostic requirements for accurately characterizing a laser-driven, shock-wave event are

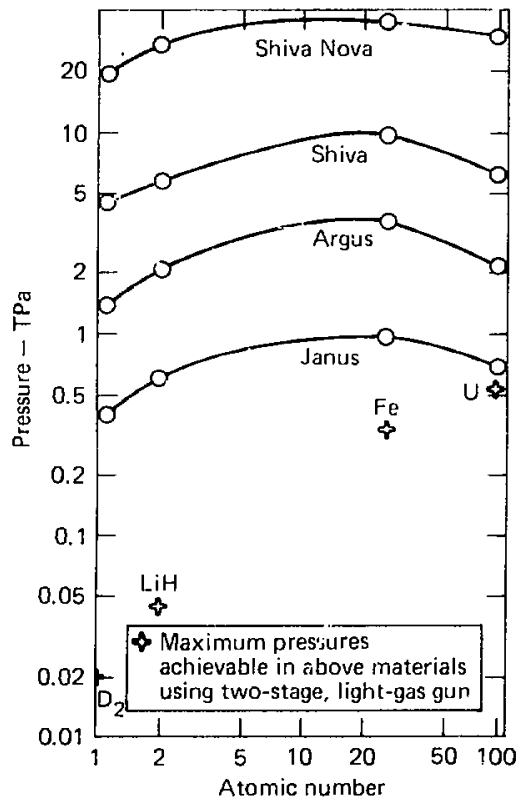

Fig. 2. LASXliX-calculated peak shuck pressures achitsuble in various materials by irradiation with different L.1.1. Iasers (pulse characteristics usted in these calculations Here 5(1)-.1/25(1)-ps

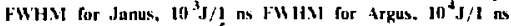
FWHM for Shiva, and 10 s. I no fWHII for Shiva Vova; all pulse's hore Guussiun). 
extremely severe. The necessity of small targets and the short duration of trpical heser pulses (no more than a feu nanoseconds) mean that any measure. ment must be mede with high spatial and temporal resolution. For example, an accurate in-target veiocity ineasurement in a 1 -mm-diam target irradiated by a 1 -ns pulse would require time resolution of $\sim 10 \mathrm{ps}$ and spatial atsoluton of $\sim 1 \mu \mathrm{m}$. We will see that such techniques are presently available and that the design of clean, accurite experiments appeas:s isasble.

In the following rection we discuss some of the properties of laser-generated shocks that must be properly understood before meaningful EOS experi- ments can be performed. Then in the section entitled "Equation-of-State Didgnostic Techniques" diagnostic requirements for ultrahigh pressure EOS experiments are discussed, and an assessment of the applicubility of various techniques to laser experi. ments is made. The section entided "Previous laxperiments" reviews the rather small amount of previous experimental work in this field. !n the seetions, "EOS Feasibility Experiment (I JPa) Ling Janus Laser" and "Argus los lexperiment Designed to Reach 2 TPa." " "e propose experiments that could be performed on the Janus and Argus lasers in the near future. And in the final section we discuss other potential laser-1:OS experimen:s.

\section{STRI ('TURE OF LASER-GENERATED SHOCK WAVES}

\&ny I US experment requires a determination of the andual and fimal atates of the material being tiuded. In a boch-uate experiment this incans that the condetum , theidd of and behind the shock front musl be meisured. In the simplest experiments the thate of the materlal athead of the shock is the ambient state and on measured before the experiment: if the inilial stale of the material is changed by some phenomenon pronapatung ahead of the shock, additumal diannumes are required to characterize this new intial stale. I has often proves to be too difficult expermentalis. and the alternative is the design of a: experment woth walficient care that the initial state is unperturbed during the experiment. This is one reyuirement of a so-ealled "clea!" experiment.

(11) of the state variables cannot in general be measured $m$ an fOS experiment. Usually, only one or two varlables are measured and are related to the other variables of the problem through the conservation laws of mass. momentum, and energy. In order to apply these laws, the geometry of the shock wave must be known. The simplest shock-wave en. periments are one-dimensional (i.c., the shock wave is planar). and the characteristic thickness of the shock front is negligibly small, In the following we will therefore be striving toward experiments that satisfy these conditions.

The fortgoing considerations require that early experiments must study the structure of lasergeneruted shocks. Putentially importunt phenomena that must be characterized include:

\section{Geometrical EIfects}

The rapid heating of a planar surface by the ab. sorption of laser entrgy produces a shock wave that is essentially spherical at distances from the surface that ure comparable to the diameter of the irradiated spot. The achievement of a planar shock therefore requires targets that are thin relative to the spot diameter. Shock planaritu can be verified axperimentally and will be diseussed under "liquation-of-Stale Diagnostic Techniques." Geonetrical effects may also te studied with twodimensional I.ASNEX calculations.

\section{Erfocts of Spatial Variation in Laser intensity}

Tae ideal laser pulse exhibits a super-Gaussian spatial variation of intensity: i.e. $I I_{0} \simeq \exp$ $\left[-\left(\tau / r_{0}\right)\right]$. where $r_{0}$ is the spot radius and $n \geqslant 5$. Thus, I is very uniform across the intadiated spot. In reality, however, the pulse may contain "hol spots." smali regions of higher intensity. due to bean breakup in the laser amplifier thatins. Theoretically. the thermal conductivity of the lister-gentrated plasma is sufficiently bigh to smooth out these hot spots as long as ( $\left.v_{\text {oxd }} v_{\text {theren }}\right)<<1$, where $v_{\text {in }}$ is the velocity of the plasma electrons in the electric fie'd of the laser radiation. and yinerm is ineir theimat velocity. This condition is satisfied for $1<10^{14}, \mathrm{~W} / \mathrm{cm}^{2}$ ? which covers the intensity regimes we'll be discussing for Jinus and Argus experiments. $A$ t higher intensities, the effects of a nonuniform laser profile on the shock struclure must be assessed carefully.

\section{Absorption Mechanisms that Depend on Angle of Incidence}

At high intensities, a significant fratetion of the absorbed laser energy may be due to resonant 
absorption, 13 which varies with angle of incidence, If the target is not situated in the Gaussian waist of the incident pulse, this mechanism could lead to a! nonuniform shock str :ture. These efrects should mot be significant at intersities below $\sim 10^{14}$ $\mathrm{W} / \mathrm{cm}^{2}$, but may become important in higherintensity experiments designed to probe heyond pressures of $\sim 2 \mathrm{TPa}$.

\section{Suprathermal Electrons}

Absorption of laser light by collective mechanisms can product: electron distributions that are highly non-Maxwellian, and the production of very-high energy electrons is particularly favored. Fxperinentally, this is a phenom:non of great importance, becuuse the long mean-fiec paths of such suprathermal electrons permil the to penetrate fiar into the target, preheating material atead of the shock and making shock compression more diflicult. This problem has been of considerable concern to laser-fusion researchets. A princigal concern in ant f:OS experiment is that proheating mas significantly alier the thermodynamic state ahead of the shock front, so that the initial conditions of the problen are effectively unknown.

(learly, targets must be designed such that the region of study lies beyond the range of suprathermal electron preheat offects. Here LAS.ViX proves inviluable. In the section entitled "HOS Fusibility Experinent (I TPa) Using Janus Laser," we will see thit the temperature profile of the shock may be strongly modified by suprathermal electron preteating: this result suggests a potentially useful means for exploring preheating effers experimentally.

\section{Radiative Preheating from Shock Front}

The very high pressure shock waves discussed here are characterized by icmperatures ranging fron several $\mathrm{eV}$ to eceral hundred $\mathrm{eV}$. Thermal radiation frequencies from these shock fronts may therefore exceed the plasma frequencies of most metals. fermitting the thermal radiation to propugate ahead of the shock frone and couple into the uncompressed matter. The consequerlec would be an effective broudening of the shock front. Such phenomena are sell documetiled in thdes of shocked gases. in which. due wo the long photon wean free paths. radiation-coupled-shocks with ch. racteristic widthe as greal as a millimeter are possible. ${ }^{1+}$ Of course, these effects would be greittly reduced in a metal: heswerer. shock widehs of esen al few mierons would be a serious problem in targets that are no more than a feu tens or hundreds of microns thick.

\section{Thermuelectric Transport Across Shock Front}

The large temperalure gradient across the shock front mas proside the means for electrons in the shock-compressed material near the front to move into the uncompressed material. I ruselling at roughly the formi velucily. which maty typieally be an order of magnilude hegher than the shock velocily, these electrons represent another possible preheat incehanisn.

The above phemomena mus be considered in

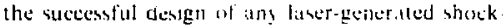
compression experiment. Ihese effects will be readdressed in the following sections on diagnowise and proposed axperiments

\section{EQUATION-OF-STATE DIAGNOSTIC TECHNIQLES}

A shock compression is fully described by the pressure $p$, densily $o$, and internal energy $E$ ahead of and behind the shock front. as well as the shock propagation velocity $u_{s}$ and material velocity $u_{p}$ The initial state $p_{0,} \rho_{0} E_{0}$ is usually known. Equations of conservation of mass. energy. and momentum relate the rimaining five unknowns. Thus, two of these five parameters must be measured to Jetermine completely $n$ equation-ol-state point, $p$ $=\mathrm{p}(\rho, \mathrm{E})$.

To appreciate the kinds of diugnostic tools that might appiy to these experiments, we should lirst discuss brietly how target dimensiums are determined, beciluse target sire and liser-pulse length together deline the ramal and temporal saikes of the problent.

The dimensions of thal disk targels are determined by the follow ing constraints:

- I.aser-irradiated area musi be small enough to pernit sufficiently high intensity. l, and thus high pressure $\left(\left.\propto\right|^{2}\right.$. approximatelyl, to be attained.

- Diameler of irradjated area must be large compared to disk thickncss so that shuck-wave propagution is essentially one-dimensional. 
- Target thickness must be large enough to permit study of the shock in a region that has not bee: proheated by fast electrons or $x$ rays produced near the eritical surface.

- Target thicknems (and. hence. shock traniit tintel must be sufficiently smiall that. after the laser power is curned off. rarefaction waves from the ablation surface do an: significantly allenuate the shoch lor later diwe sion we refer to this characleristic thickress as talc "rarefaction ange."

$10:$ significunt measurable pressures (20.) IP:1) (1) be produced with a Janus pulse $(\approx 300 \mathrm{ps}$ : the above considerations require a target les than $50010101000 \mu \mathrm{m}$ in diameter and 30 to 5il $\mu$ m thick. Shock velecities for the pressures discussed in thus report atre expected to range from 20 to si) $\mu \mathrm{m}$ nn. The (ransit times for such shock: lirough fands largets maly therefore de no more than a few nu: the delines the lotal durtion of the esperment. In ascurate temporal characteriziation al anl naterial property on this time scall: therefore require unusually precise resolution. on the order (1) a tew piconcconde 1) dagnostic tools used in conventinnal bhock-uate experiments. (e.g. selfhorting elcetroal pme respond mucl, too slowly (a few hundred painecondol to be of use in these experinems. He mtist therefore consider whether malerial propertaes can be measured witi meiningiul acturaty on the time and spatial seales defined abore.

Infortunately, in an EOS experiment it is usuall! not !rosuble to measure accurately P.p, and I direcil: Whal can be readily measured is $u_{5}$, and ue diecuss belem huw this nay be done in laser EOS expermments. He also dixcuss a polential method for meiluturmg $u_{\Gamma}$.

\section{Shock Velocity Measurements in Metals}

This technique uses an uttrafast stresk camera to measure the temporal depencence of the brightness of a netullic target surface (see fig. 3). The thermal radiation produced by the high. temperture shock front will betome visible to the streakl camera only when the shock has advanced to within a few skit depths. $\dot{n}$. of the surface. As the shock proseresses to the surface, the surfare brightness will increase until the silock breaks out of the frec surface, at which lime rarefaction and rapid cooling ensue. The rise time of the signal recorded

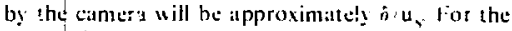
optical-frequency components of this signal, whicht will te recorded by the streit cantera, $\delta \sim 0.1 \mathrm{~km}$. In aluminum, for exanple, at 2 TF: $u_{q}=30$ $\mu \mathrm{m} / \mathrm{ns}$. The arrival tine of the shock it the free surface could therefore a determined to within -3 ps hy accurately recording the onset of this optical signal. This uncertainty is cr mpitrithle is the time resolution ( lli pr) of the streak cameras presently used in laser fusion restarch ill Li.l. ${ }^{\text {Is }}$

The feasibility of studying the hizhtemperature shock front on a 10 -ps time se ic would permit us 10 assess experiment:ally some of the phenomela discussed in the previous section (supratherm $\cdots$ : electron effects. sausative heating from tiae shock front. etc.), becal'se if they occur. they would add temporal structure to the radiated signal. Obviously, if we cannor see such effects on this time scale. they play do significant role in the problem. We can atso study the spatial distribution of the thermal radiation with spatial resolution near $10 \mu \mathrm{m}$ by appropriate magnification in the streak camera imaging opties. Thus, by studying the ten-
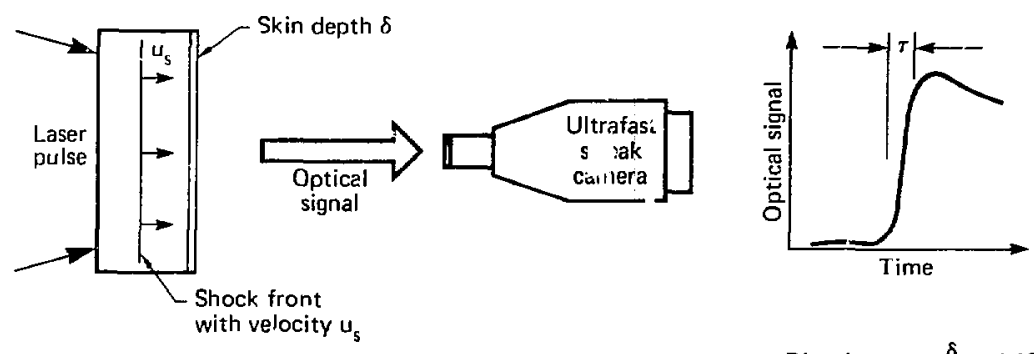

Rise time $\tau \sim \frac{\delta}{u_{s}} \leqq 10 p s$

lïg. 3. Optical neasurement of shock urrival times at metat sur Faces ( hecause visible thermal rndiation produced hy whock heating will he seen by the struak caraera only aftur shuck has advanced to within a feu skin-depths of the frec surface, camera nill recerd a rupidly increasing signal ]. 
poral and spatial history of the thermal radiation emitted across the rear face of an irradiated disk, uniformity of the shock can be assessed.

By measuring the arrival time of the shock at two precisely measured steps on the rear surface of a laser-irradialed disk, a shock velosity may be obtained (see Fig. 4). For a step height of $25 \mu \mathrm{m}$ and $u_{s}$ $=30 \mu \mathrm{m}$, an average shock velocity may be measured with in accuracy of $\sim 2 \%$, assuming that the steps are smoooth to within a few tenths of a micron and that tieir sepatation can likewise be meusured to within a few tenths of a micron; this is reidily achievable.

With the long pulses ( 5 to $10 \mathrm{~ns}$ ) that are possible only on the higher-energy lasers, Argus and Shiva, targets may be nade, larger, because the rarefaction range increases. For a 10 -ns pulse a step height of 75 to $100 \mu \mathrm{m}$ could be used, and a consequẹnt shock velocity meisurement accurate to $\sim 1 \%$ may be expected. This approaches the accuracy possible with the best present techniques, used in conventional experiments at much lower pressures.

\section{Shock Velocity Measurements In Transparent Solids}

A technique for measuring shock velocities in initially transparent targets was first suggested by van Kessel and Sigel. ${ }^{16,17}$ The method, sketched in Fig. 5, consists of bucklighting the target normal to the direction of shock propagation with a small visibit-light laser, $A$ s the shock propagates through the target, material is ionized by the high pressure and temperatures. and the target becomes opaque to the backlighting source. An ulirafast streak camera is used to obtain a temporal and spatial record of the opagning of the target. This record permits a shoek velocity to be determined. The acduracy of this technique is limited hy tine and spatial resolution of the camera. For example, $1-\mu \mathrm{m}$ spatial resolution and 10-ps time resolution are required to determine the shock velocity of a 25 $\mu \mathrm{m} / \mathrm{ns}$ shock to $2 \%$ accuracy.

Ore problem, inherent in this diagnostic, is the question whether the ionization front can be
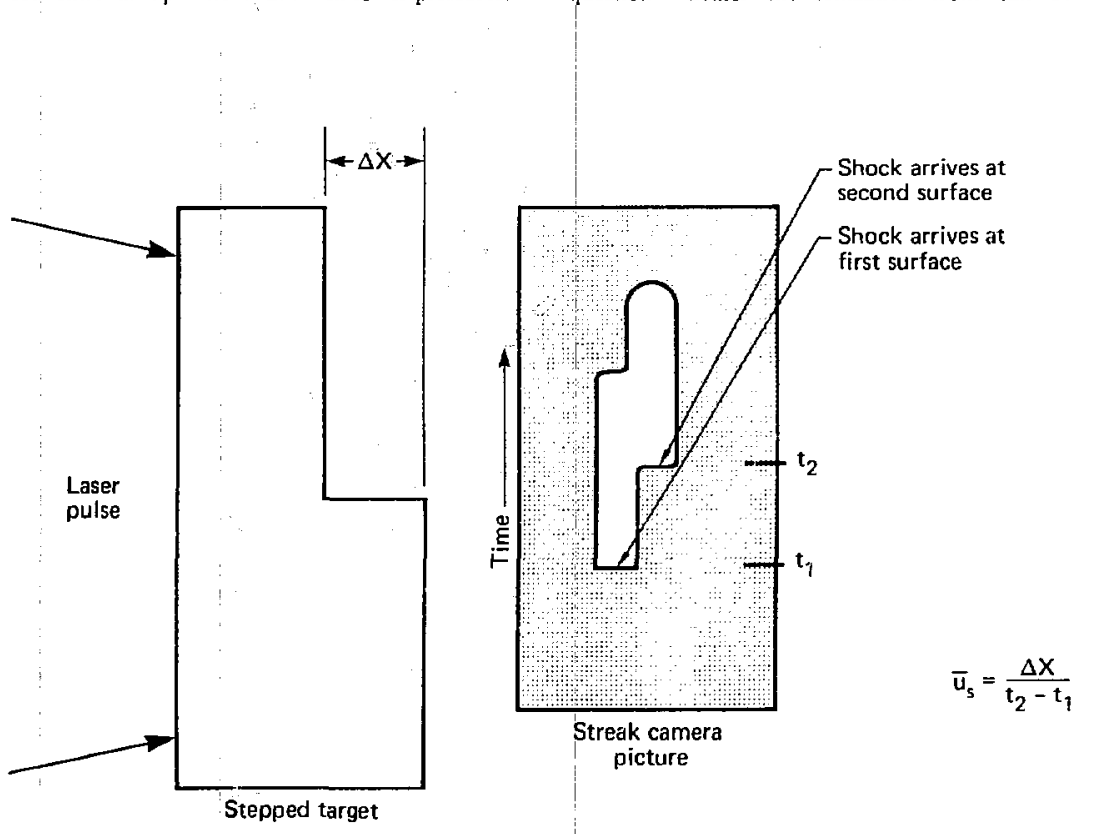

Fig, A. Sketch of idcalized streuk-cantera photograph shoring optical signals correspending to shock broakuut at iwo surfucus on stepred tacget. 


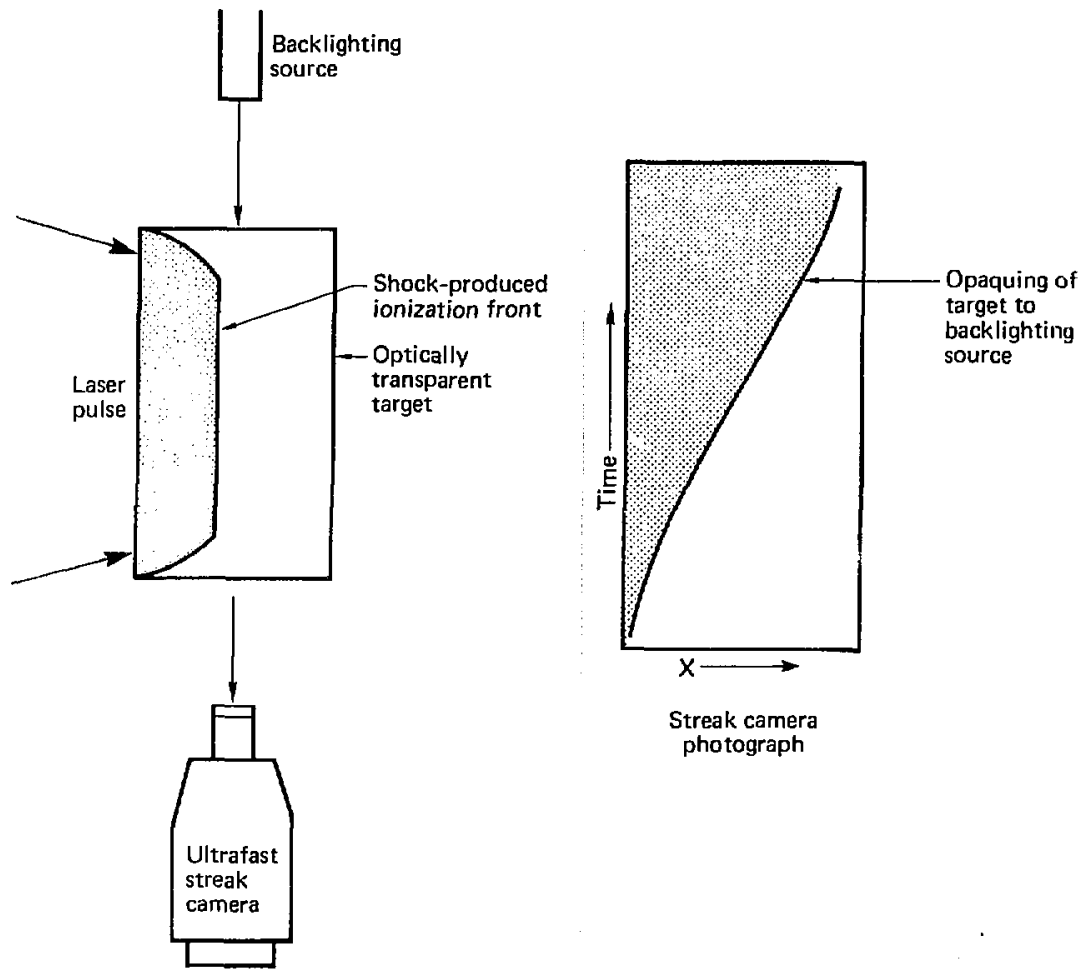

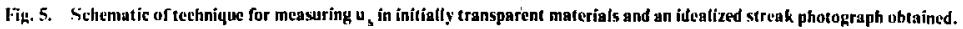

associated with the shock front and not with preheating effects. Resolution of this question requires either a good ionization model (which demands very low Z) for the target and a quantitative understanding of preheating effects or an additional diagnostic. A possible diagnostic is sketched in Fig. 6. Here the experimental configuration is idenlical to that in Fig. 5 , except for a thin metal disk at the bottom of a narrow notch facing the oncoming shock wave. By observing the onset of motion of the disk, the arrival time of the shock can be ascertained.

Two spatially resolved dimensions of the shock propagation may be obtained by using a modelocked dye laser, with pulse lengths of about 5 ps at $\sim 2$-ns intervals, as the backlighting source. In this method, the streaking rate of the camera is slowed down and the slit opened up to a few hundred microns. If the streaking rate is slow relative to the 5-ps pulse duration, then a series of two. dimensional images is produced on the film. This technique would prove especially useful for study ing the geometrical effects mentioned in the previous section.

\section{Particle Velocity Measurement}

A possible technique for measuring the particle velocity behind the shock front employs the ultrafast $x$-ray streak camera developed in the LLL Laser Program. ${ }^{1 B}$ This instrument, presently used 

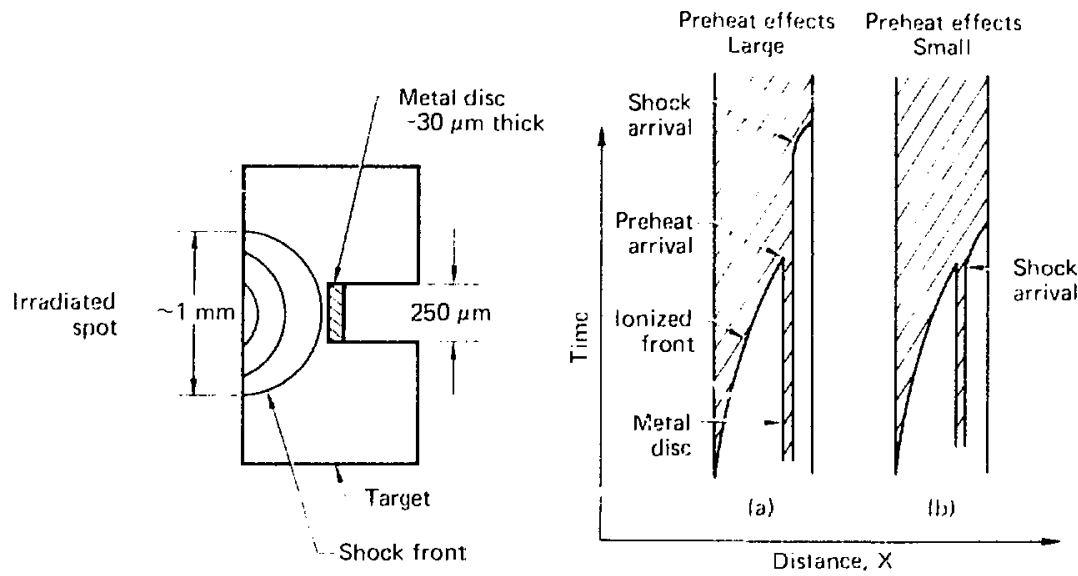

Schematic streak photos

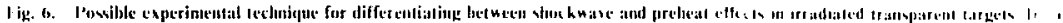

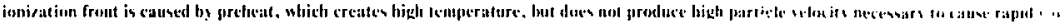

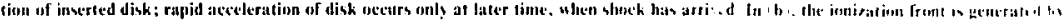

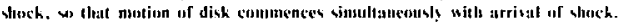

for space-time studies of $x$-ray emission from $\mathrm{im}$ ploding laser-fusion targets, offers simultaneous lemporal resolution of $15 \mathrm{ps}$ and spatial resolution of $6 \mu \mathrm{m}$. It has a neirly energy-independent response to plutons in the $0.3-10-8-\mathrm{keV}$ range. $A \mathrm{n}$ experimental arrangement for particle velocity measurement is shown in Fig. 7.

The target is composed of two adjoining slabs, chosen to have greatly differing photon cross sections in the energy range of the $x$-ray source, ont being essentially transparent, the other opaque to the $x$ rays. For a source energy of $10 \mathrm{keV}$, suitable examples would be $\mathrm{LiH}$ and $\mathrm{Al}$. The $\mathrm{x}$ rays could be generated by the beam not used for tirget irradiation.

A backlighting technique is then used to observe the transit of the target interface across the field of vicw of the streak camera $(\sim 100 \mu \mathrm{m}$ at $50 \mathrm{X}$ magnification). The velocity of the interfuce is equal to the particle velocity on either side of the interface. It is possible that the opacity of the transparent material will vary sufficiently upon shock compression that the shock front could be also observed in the streaking record. Neglecting diffraetion effects, the accuracy estimated for this

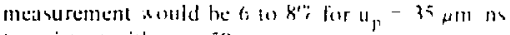
(tonsistent with $u_{、}=50 \mu \mathrm{m}$ not

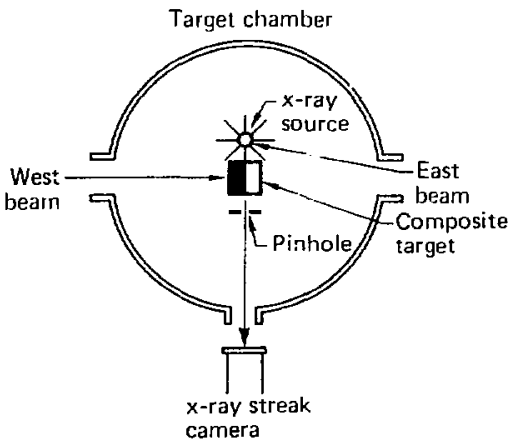

lig. 7. Possihle parficle-selocity diagnostic utilizing ultrofast kray streak camers. 


\section{(Jher I'ropert? Weasurements}

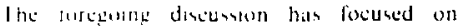
iclachl Micisurements on the abock-sompressed : arete: I bese tre the anly properues that appear

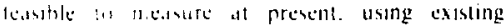

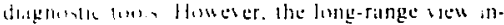
buder the dente attd nesessily to measure ad

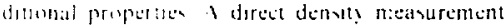

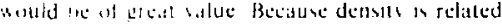

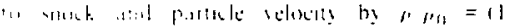

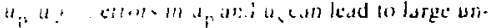

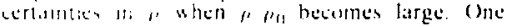

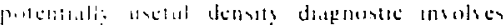

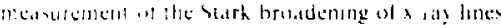

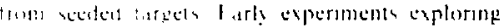

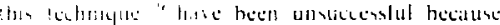

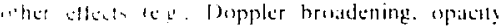

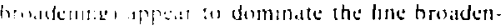

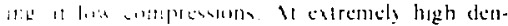

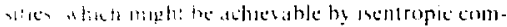

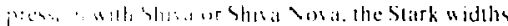

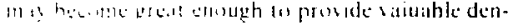
(i) $111+1 ! 111,1,016$

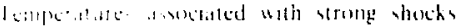

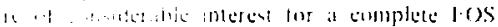

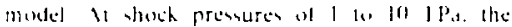

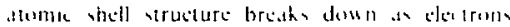

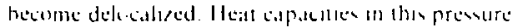

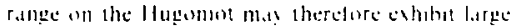

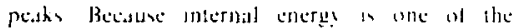
paramelers ahtabled from a vhoch wace expers.

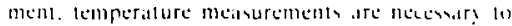

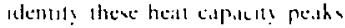

Ihe lame durattans at the experdments con.

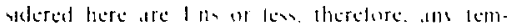

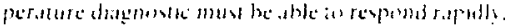

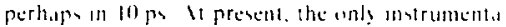

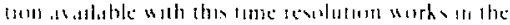

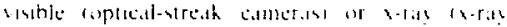

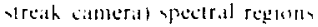

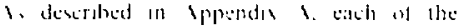

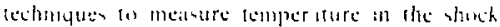

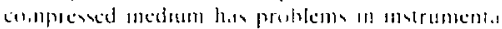

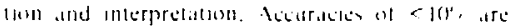
probibls heeded a the mcisurements are ob he

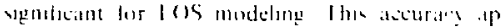

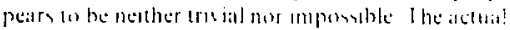

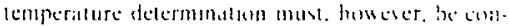
sidered a a second genterallan expesmest

\section{PREVIOIS EXPERIMENTS}

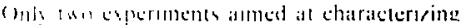

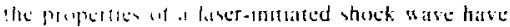
hen repulted , Ih the literalure. I an Kessel and

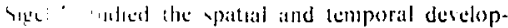
men: moch $>$ gencraled hy a 20 ). 5 - 5 - laser pulse

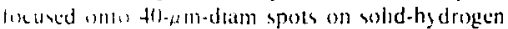
and plevglass bithe. The hatklighting shockveloctly diagnatic discussed in the previous section win cimplesed. Ihe observed phenomenon was hgyhly andunensmonal. due to the small ir radiated spos lan untortumate necessity with lasers of only morderale poucr)

A maximum shock velocity of $38 \mu \mathrm{m} / \mathrm{ns}$ was found for the hydrogen target. Using an extrapolation of $\mathrm{J}$ (OS measurements made al much lower pressures, 2) a peak pressure of $0.2 \mathrm{TPa}$ was eslimaled. This figure is rather inpressive, because the highest pressure achievable in hydrogen by any other in-laboratory ineans is about $10 \mathrm{GPa}$ in a single shock. However, the pressure estimated above is in rather poor agreement with that predicled by one-dimensional code calculations that predict a miximum pressure of about 2.1 TPa in this experiment. This substantial discrepancy between theory and experiment is primarily due to the two-dimensional nature of the shock front. Our l. ASNtX calculations also indicate that suprathermal-electron preheat probably played an inportant role in this experiment as well. These results point up the necessity of understanding the phenomena discussed in the section entitled "Structure of l.aser-Generated Shock Waves." Nonetheless, this experiment represented the first direct observation of a laser-initiated shock wave and was the first to indicate the potential of similar experiments to high-pressure research.

Billon el al. "I studied the propagation of laserinitiated shocks in aluminum and $\mathrm{CH}_{2}$ targets, using both planar and cylindrical geometries. A planar $\mathrm{CH}_{2}$ target was irradiated with a 30-J/3-ns pulse focused on a $60-\mu \mathrm{m}$-diam spot. The shock-transit time through the $30-\mu \mathrm{m}$-thick target was measured by an interferometry technique, ising the first harmonic of the incident laser light $(0.53 \mu \mathrm{m})$ as a diagnostic beam and fast framing cameras to photograph the interferograms. The entergence of the shock from the rat target surface was clearly seen about $1.5 \mathrm{~ns}$ after the initial interaction with the laser pulse. The estimated mean shock velocity corresponded to a pressure of aboul $0.17 \mathrm{TPa} . A$ 
I.ASNitX study of this experoment has not betn performed, but we can conclude from other IASNl:X calculations that suprathermal-electron effects were undoubtedly severe in this experiment.

In the experiment with cylindrical geometry, an aluminum tuhe, $245 \mu \mathrm{m}$ in diameter and $67 \mu \mathrm{m}$ in wall thick ness, was symmetrically irridiated normal to the eylinder axis by four laser beams. A total of aboul $190 \mathrm{~J}$ was deposited in about $5 \mathrm{~ns}$. The area of irradiation wats not given. The breakthrough of the shock was detected by observing the extinetion of fight from a probe laser aligned along the lube axis. A symmetre extinction of the probe light was ob. served. Indicating that bigh thermal conductivity smonthed any discrepancies in nonuniform illumination. The shock transit time corresponded to a) pressure of $-0.27 \mathrm{~Pa}$.
These results are in isong disagreement with the higher theoretical prediclison, of the pressure This discrepancy has been altributed parlalls to the effects of lateral thermat conductuon: i.e. the area of the ablation Iront is much greater than the area of the focal spot due to lateral transport of enefey be. tween the critcal surlace and the ablatuon front. A substantially larger fixal spol wall elimenate segnifs. cant effects due to this phenomenon. The much higher powers produced by the I.I.I. lasere maike this possible

We nou discuss the desgen of tha los experi. ments using the Janus an.1 i raus lasers and firected at measuring matterial propertes in the 1-101-2-! Pis range

\section{EOS FEASIBILITY EXPERIMENT ( 1 TPa) USING JANUS LASER}

One of the standard methods of shock-wive 1.0S measurement is impedance malching. The technique involves the propagation of a shock from a known slandard materiat into an unknown sample (or vice versa). By measuring $u_{s}$ in both malcrials and matching boundary conditions, one can determine the 1:OS of the unknown relative to that of the slandard. Because only a measurement of $u_{s}$ is required. our first series of experiments will be of this type. We now present results of a one-dimensional I.ASNEX study of an impedance-matching experiment appropriate for the Janus laser.

A possible target for these experiments is shown in Fig. 8. The shock-velocity diagnostic discussed under the heading. "Shock Velocity Measurements in Metals," would be used to measure the history of thermal radiation emitted from each of the stepped surfaces. We stected aluminum and tungsten us the two sample materials for this study; however, the number of feasible and interesting combinations is large. Aluminum is typical of low- $Z$ metals, for which our theoretical understanding is best (another example would be beryllium), whereas tungsten represents the many high-Z metals for which our und "tanding is rather poor. The muximum pressures achieved by conventional means in these materials are about $0.2 \mathrm{TPa}$ in $A 1$ and $0.5 \mathrm{TPa}$ in $\mathrm{W}, 20$

A 50-J/250-ps FWHM Gaussian pulse im: pinged upon a $500-\mu \mathrm{m}-$ diam spot on the Al surface. About $30 \%$ of the incident radiation was absorbed.

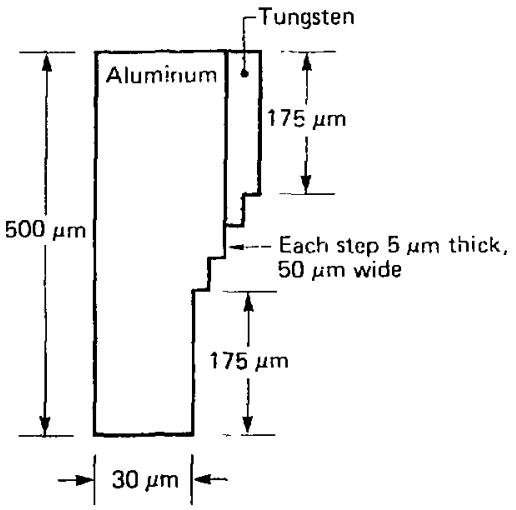

lijg. 8. 1.dSYkg-designed aluminum-qunguten impedancematching targec for Janus experiment.

Suprathermal-electron generation in the $\Lambda$ was characterized by $a=6$.

\footnotetext{
*In I.ASNEX, suprathermal telectrons of velucity $v$ are produced by a source function varying $d s v^{2} \exp \left(\cdot v^{2} / \alpha v_{t}^{2}\right)$. w here $v$, is the mean thermal electron velocity. The porameler a characterizes the encrgies of the suprothermals and is chosen such thit calculations reproduce the high-energy features of measured $x$ ray spectra.
} 


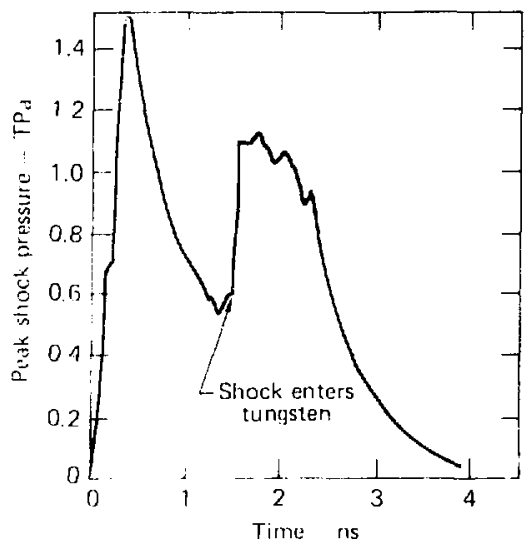

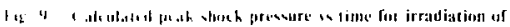

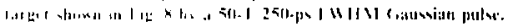

I leure 9 shows the calculated peiak these pressure plolled is lame. I peak pressure o! absu:

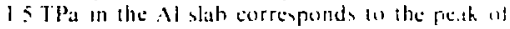
the liser pulac at $300 \mathrm{p}$. As the liser puriec decredses, rarofaction wate from the dhlitwon frebl overtike the shock and $p$ decredse. Bs the tume the

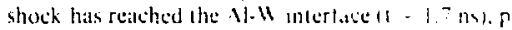
has decreased to aboul 0.6 TPal. Becianse of the

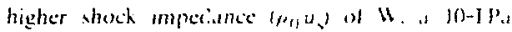

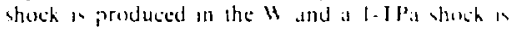

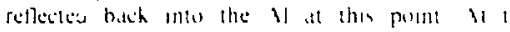

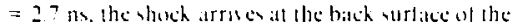

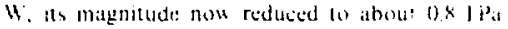
Pressures of the magnetede coceed lihose achos able in ans materal bs ans prescoll intabusaturs means a) 111

f's abeat ellects can be oblithed from I le 10 .

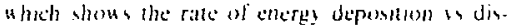
fince $\rightarrow$ anto the larget at $1 \quad 300 \mathrm{~m}$, the peith of the later pulse. The iss vource af probeitung shown are wprahermal electrom and $x$ rals generaled

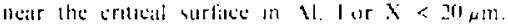

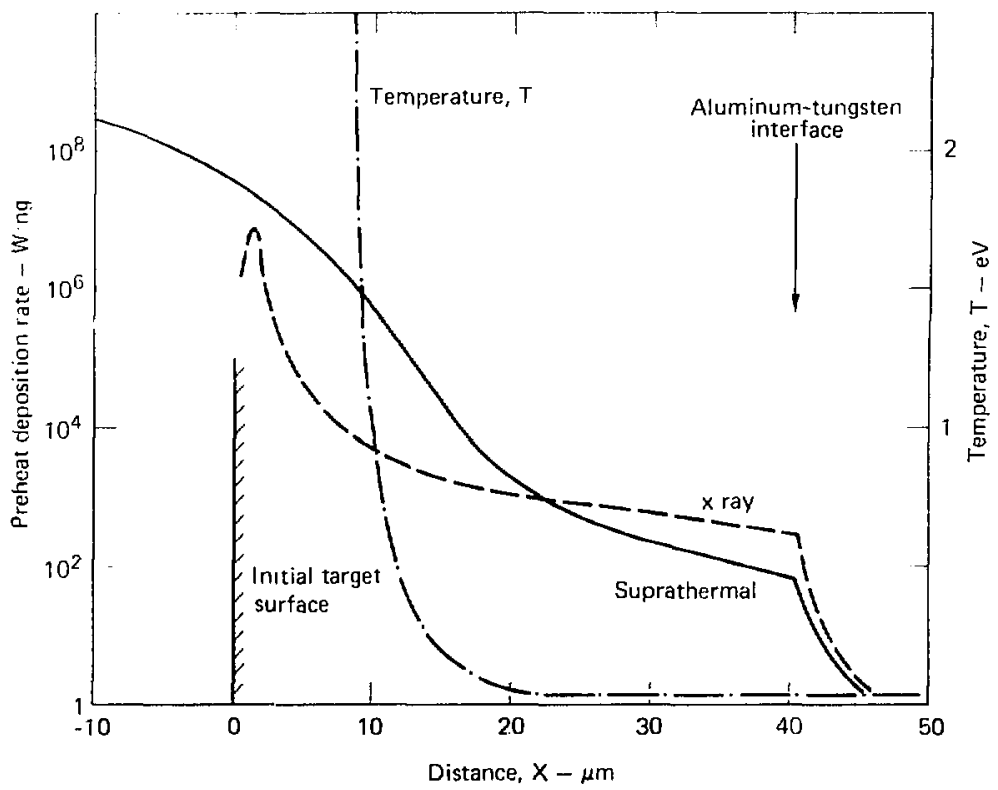

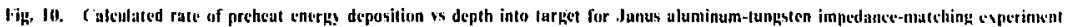
(tinut = 3lil pes at peak of pulse'). 
suprithermal electrons are seen to be the dominant proheating mechansm. Beyond $X=20 \mu \mathrm{m}$ preheating effects are not important, as can be seen by the plot of temperalure $T$ w $X$ in Fig. 10, where $T$ drops from I eV at $X=10 \mu \mathrm{m}$ to less than $0.1 \mathrm{eV}$ at $\mathrm{X}=18 \mu \mathrm{m}$. This temperature eompares with a value at the shock front of abo.t $6 \mathrm{cV}$. Another potential source of preheal is blackbody radiation frem the shock front itself r see "Structure of lastr(icnerated Shock Wave"). To assess the impor. tance of this phenomenon. Jou-energy groups were included in the photisl group structure. However. effects al such a precursor did not appear sagnilicin! at these shock temperatures. Once the shock was travered $x=15-10-20$ um region. pressure and temperature profiles steepen significtotly. their sidths apparenty delermined only by eone thicknesues, We note that our onc-dimensional citlculations do not include the efrects of selfgerieraled magnetk fields, which are expected to enhance suprathermal-eletron lemperatures. To alecounl for this effect, the first free surface of the larget ahown in l-ig. 8 was positioned at $X=30 \mu \mathrm{m}$.

As discussed previously at sharp turn-on of the oplisit ugual tenitted from eilch step is expected. The I SSNFX calculations support this idea. pigure 11 shows the electron temperatures ats functions of time !or various target depths. The expected sharp turn-orn of thermal radiation* is charly seen. Sear the rear surface $(X=49 \mu \mathrm{m})$, where zoning is fnest, an oplical-signal rise time of $\leqslant 10 \mathrm{ps}$ is calculated. It is interesting to note the early-lime temperatuse rises due to suprathermal-electron preheat. ligure 11 illustrates how a high preheal level may broaden the last turn-on of the optical signal and lead to a spurious shock-velocity measurement. This result suggests, in fact. an in. teresting series of experiments to study fast-electron preheat effects by measuring the time dependence of the free-surface brightness of a thin foil.

The 5- $\mu$ m-step thickness shown in Fig. 8 is chosen as a compromise between the desire to sample $u_{s}$ at us many depths as possible (since $u_{s}$ is timedependent), the necessity to make the shock transit time long compared to the time resolution of the streak camera, and the constraint of keeping the target thin. Also, this thickness should be large compared to the roughness of the step surface $(<0.5$ $\mu \mathrm{m}$ for a carefully prepared surface). For a $5-\mu \mathrm{m}$ step we thus expect shock velocity measurements in

- For the several-ev temperatures discussed here, the peak of the blackbody function occurs at wavelengths so much shorter than those to which the cantera is sensitive that variations in optica! signal $n$ ic roughly proportional to variations in $T$ (RalyleighJeuns timit).
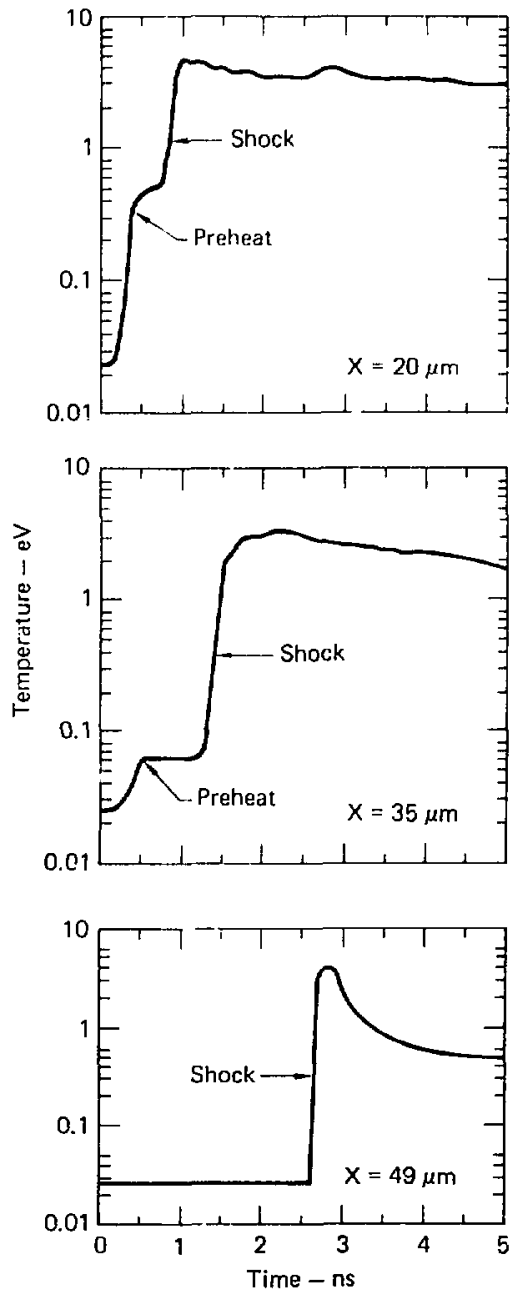

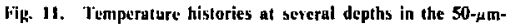
thick aluminum-tungsten impedence-matehing target shown in lig. 8 ( $\mathrm{X}=$ distance from initial irradiated surface; time = zern when leading edge of laser pulse firsl hits (arget).

a Janus experiment to be accurate to $15 \%$ or better. While a $u_{5}$ measurement of $15 \%$ accuracy is not sufficient to improve significanliy our present EOS 
modela. It is more than adequalc to establash the feashelaty of luser-shock-Mate experiments, to study preticat effects. to lest code predictions, and to deselup diagnostc capabilities. These would be the goals of lanus experiments. As mentioned previously, with long puises ( $>1 \mathrm{~ns}$ ) the highaccuracy measurements necessary to provide useful fOS data may be made.

\section{ARGUS EOS EXPERIMENT DESIGNED TO REACH 2 TPa}

Ihe ultumate dicuricy of a Janus I:OS experinent an which veterdtes are measured) is limited by the thort pulate lengll,. Short pulse length also presents ur from making oplinum use of the laser's pres'tre-producing cispabilaty. hecause rarefaction "aven wabluntalit: reduce the pressure at the shoek Iront belore it hav travers :d the prebeated regich, of the larget ree 1 g 9). These constraints can be anercoms in an trgus shock-save experimert. in wheth neurls rquare pulses several nanoseconds longe are pomithle

I feure 12 shisu the lime dependence of the I IS VI 8 -preduted hock preseure in a 1 -mm-diam W.W impedance.matching larget irradiated by a 3 . h. 3 . $n$. " $3(0) 1.130)(1-p 4111111$ pulses at 300-ps intorvals. Here we ute at II,K.T Pa shock is generated in the Al and $|K-l| P_{i}$ formard and reflected shocks are produced at the MI-W interface. Note that, because of the loneer pulse length. this higher pressure experiment is actually achievable with a lower intensit: than that propesed for the Janus experiment.

in assessment of preheat effects reveals a preheilted region of about $90 \mu \mathrm{m}$. At this depth. I. ASNI:X calculations indicate suprathermal electrons heat the material to about $0.1 \mathrm{eV}$. A possible impedince-mutching target is shown in Fig. 13. The high pow'rs and long pulse lengths achievable with Argus permil the use of a significantly larger target thun that required by Janus. Note that step thicknesses for the Argus target are $25 \mu \mathrm{m}$, compared to the $5-\mu \mathrm{m}$ steps of the Janus target. Shock velocity measuements accurate to about 2 to $3 \%$ should therefore be possible in a 3-ns-pulse Argus experiment. With a 6-to-10-ns square pulse, shock velocity neasurements uccural: to about $1 \%$ appear possible. The uccuracy of an Argus EOS experiment, therefore, should approach that possible with conventional techniques (i.e., HE and two-stage gas guns), which operate at much lower pressures.

The transil time for the shock across the four steps of the Argus target shown in Fig. 13 is about $5 \mathrm{~ns}$, which exceeds a streak-camera writing time $(\sim 1.5 \mathrm{~ns})$, if 10-ps time resolution is required. It therefure becomes necessary to time-delay a portion of the optical signal. This delay could be achieved by mounting the arget directly against a coherent bundie of low-dispersion optical lihers, as iflustrated in fig. 13. Outside the target chataher, the bunde may be separated and the signals iouted through appropriale optical delays.

We summaries this section by noting that in an A rgus EOS experiment:

- Pressures approaching $2 \mathrm{TPa}$ can be produced in a simple impedance-matching target. Pressures this large have not been previously produced by any conventional means.

- Aceuracy of an Argus experiment should approach that possible with the best present inlaboratory technique, the two-stage gas gun, which is limited to lower piessures.

Figure 14 compares p'ssible Al-W impedance matching experiments performed with Argus, Janus, and the $H$ Division two-stage gas gun. It is seen that the capabilities of the LLL high-pressure research effort could be significantly extended into interesting and relevant regimes by the successful development of the experiments we have discussed.

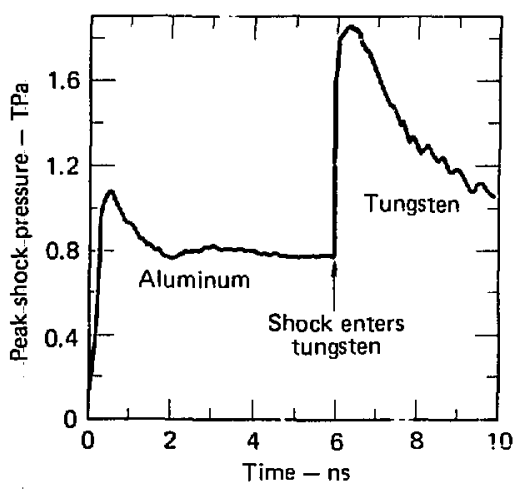

Fig. 12. Penk shock pressure is time in Argus impedancematehing experiment. 


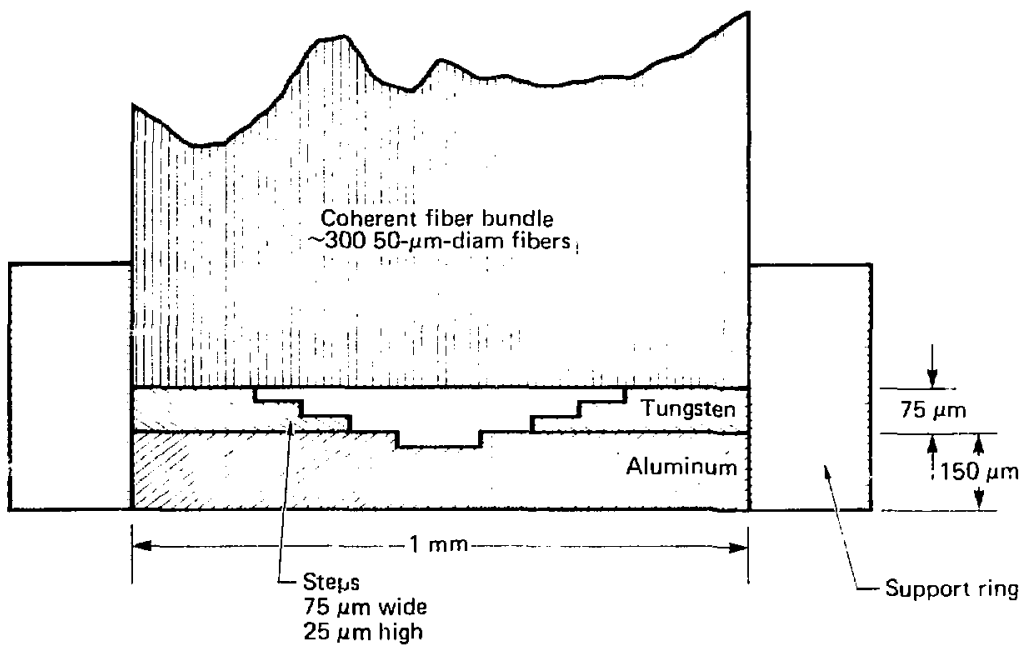

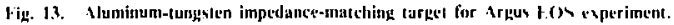

\section{OTHER POTENTIAL LASER-DRIVEN EOS EXPERIMENTS}

This report has concentrated on shockcompression experiments, because they appear to be the most feasible candidates for first-generation experiments. However, laser irradiation of malter can produce a rather rich variety of material states, and it is important to consider other potential EOS experiments of interest.

\section{Other Shock-Wave Experiments}

These include multiple-shock, expanded initial state shock, and blast-wave experiments. Multipleshock experiments would be of interest because they permit study of material states closer to the principal adiabat than the principal Hugoniot. Valuable temperature data could be obtained from such experiments. The production of the multishocked state should be readily achievable with the multibeam lasers at LLL. Expanded initial state shock experiments would be of interest in exploring the high-temperature side of the principal Hugoniot True blast-wave experiments should be possible with the very short pulses (down to $\sim 30 \mathrm{ps}$ ) possible with the LLL lasers. Thus, the attenuation of the laser-produced shock should be described by setfsimilar relations very early in the experiment. An integral blast-wave experiment has been proposed by Grover ${ }^{22}$ It is estimated thal pressures above I TPa could be measured, if $\lambda$ rgus were used as the energy source.

\section{Isentropic Compression}

Stales near the principai isentrope can be achieved by properly tailoring a high-energy laser pulse so that the irradiated material actualiy experiences a long sequence of shocks. Experinients in this regime would be highly desirable, because they could provide direct tests of the APW band-theory calculations discussed in the section entitled "Pres- 


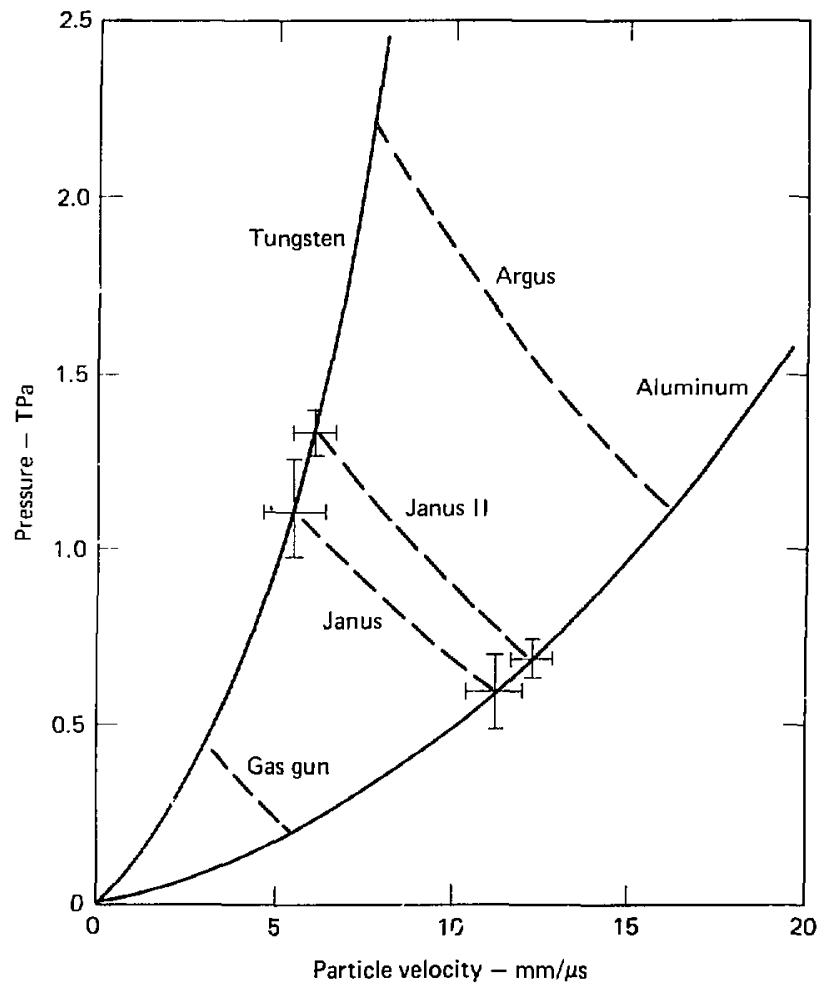

Fig. 14. Comparison of tarious uluminum-tungsten impedance-matching experiments f solid curses reprewnt $1 /$ and $\mathrm{W}$ principal Huzuniots; dashed curves represent rellected Hugoniots at AI-W interfacer.

ent Status of Theoretical and Experimental EOS Research."

\section{Expansion Experiments}

The efliciency with which $x$ rays and highenergy electrons are produced by laser-matter interaction suggests potentially important expansion experiments in which material is heated nearly uniformly throughout its volume. The resultant material states would approximate an isochoric heating followed by isentropic expansion of the hot plasma. Such EOS paths in the multi-eV region would provide experimental data in the dense partially fonized plasna regime (see Fig. I).

\section{Accelerated Flyer Plates 2.3}

Experiments of this type would use laser-driven ablation to accelerate a Myer-plate, which would subsequently impact the turget, generating a highpressure shock wave. The potential advantage of this. technique is that the target would not be subjecto's to suprathermal-electron preheat, nor would there be contert about structure in the shock profile due to variations in the laser-pulse profile. 


\section{CONCLUSIONS}

We have seen in this report that the ILLL highpower lasers offer the potential to exiend significantly the present range of EOS experiments. Pressures in the 0.5-to-30-TPa range could be achicved with racilities either presertly in optration or planned for the next five years. Thus, a pressuredensity regime of great theoretical uncertainty could be addressed for the first time by laboratory experiments.

To illustrate the potential vilue of accurate ultrahigh-pressure, shockwave experiments, we show in Jig. 15 a plot of shock pressure vs density for beryllium. Shown here are the available experimental data, extending up to $\sim 0.1 \mathrm{TPa}$. as well as the principal Hugoniol calculated from two theoretical models. one the well-wstablished TI.D. based 1:OS of Cowan. ${ }^{24}$ the other a recent sheilstructure model from (iraboskt and Wong. " 2 iote the asymptolic agreenient belween the models-it lou pressure where the models can be normalized to experimental data and at extremely high pressures ( ) $100 \mathrm{TPa}$; were forsl principles theory become

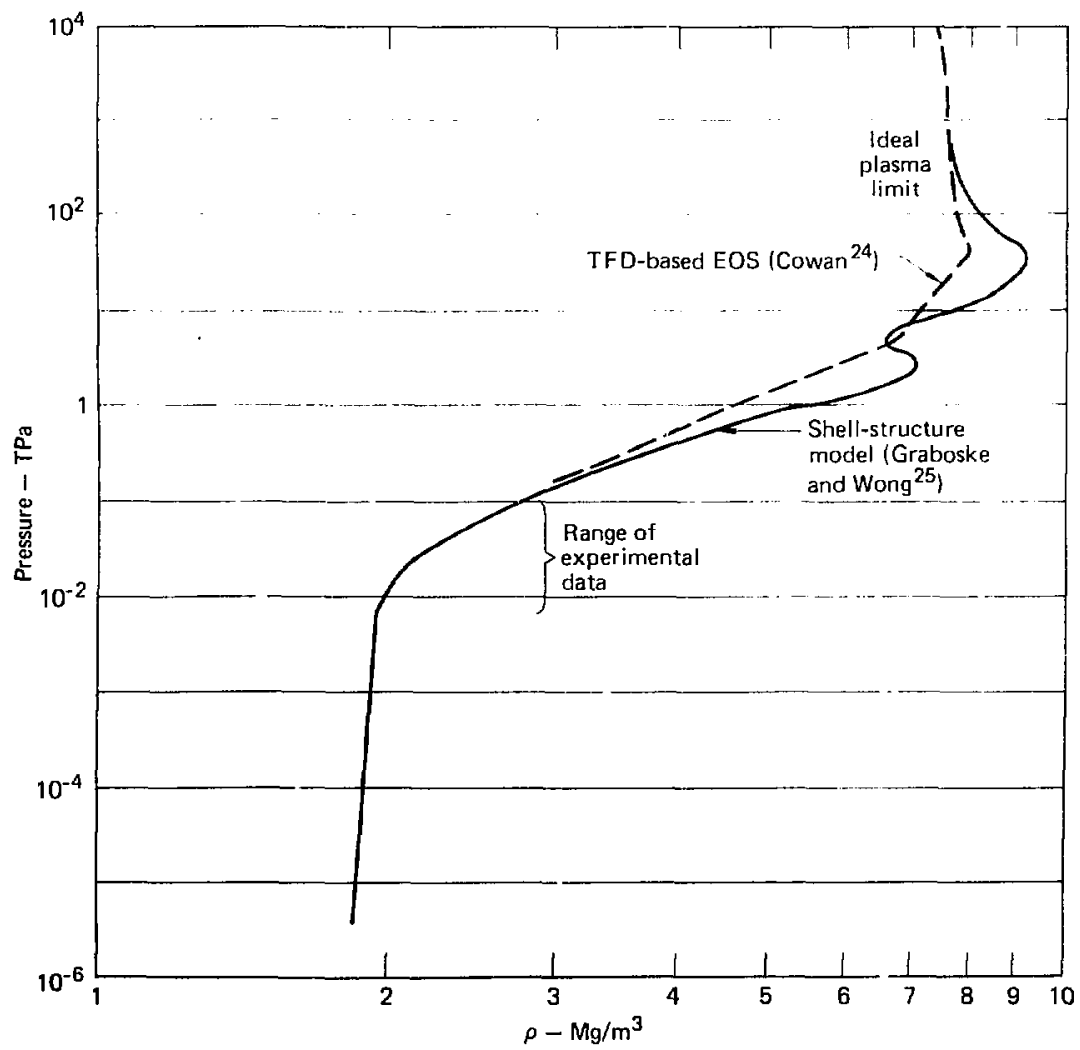

Fig. 15. P'rincipal Hugoniot of beryllium calculated from two theorelical models, TrD)-hused F.OS of (iuman and shall-structure model of Graboske and Wong. 
relable. Howeser. in the intermediate range I to $100 \mathrm{TPa}$. the iwo models predict densities for a gren pressure that differ by as much as $30 \%$ for this simplest of metals. This difforence is illustrated in Fig. I6. Clearly, shock wave data of a few percent accuracy in this pressure range would be invaluable in ussessing the validities of these models.

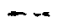

1 ig. I6. Iractienal difference between culculated dentigies of locrollium alonge principal Hageniot betheen J J-12-baved and shell. areclure tos mendels us a function of pressure.

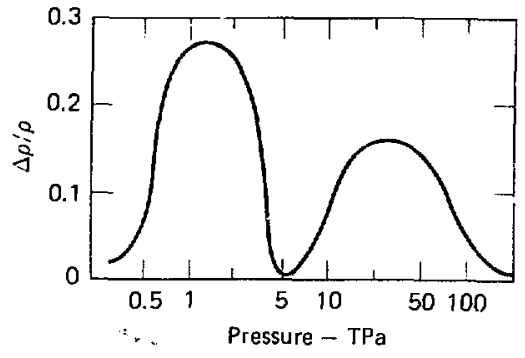




\section{APPENDIX A \\ TEMPERATURE AHEASUREMENTS IN LASER-SHOCKED MATERIALS}

Conventional pyrometric techniques for determining the temperature of gray body radiators operate best on the high-frequency side of the black-body spectrum. In this spectral region the radiant intensity increases as a high power of temperature. However, the intensity also drops off with increasing frequency like exp (-hw/kT): therefore, operating at frequencies too far above the blackbody peak results in a small signal-tonoise ratio and inaccurate temperatures. Depending on the details of the detector response and the noise spectrum, an optimal energy range to work in is 2 to 5 times the energy of the blackhody peak, or 9 to 25 times kT of the radiator.

For shock experiments between I and $10 \mathrm{TPa}$, the temperatures will be between 5 and $100 \mathrm{eV}$ for various materials. Thus, only at the highest temperatures could the $x$-ray streaking camera be operated in an optimal spectral range. For all such experiments, the optical streaking camera will operate in the Rayleigh-Jeans tail of the hlackbody spectrum, where the radiant intensity is proportional to $T$. Therefore, meaningful pyrometry with optical radiation will require absolute intensity measurements of accuracy better than $10 \%$. On the other hand, the $x$-ray measurements may be made with considerably less accuracy, but one must anticipate a noise probiem. especially from the expanding laser-generated plasma.

The geometry of the radiation pyrometry experiments will depend on the type of materiat studied. lior an opaque material like a metal with visible radiation, residual temperature of a free surface after shock and release back to zero pressure can be measured, ${ }^{26.27}$ The residual temperilure. although interesting. would be confused by the fact that even if the relaxed matertal is in it homogeneous equilibrium state. is will he an expanding. highly ionized vapor with a varying opacity. In order to measure the temperature associated with a state close to the principal Hugoniol, a metal must be backed with a transparent anvil. ${ }^{28}$ At the shock pressures associated with the experiments described here, we know of no optically transparent anvil mattrials. Thus, direct optical pyrometric temperature measurements on metals shock-compresced to > I Pa will be very difficult without significant increases in the time response of our diagnostics. $A l$ the higher pressures, $x$ ray pyrometry may work adequately, but opacities and noise sources must be well characterized.

The situation may be much simpler for optically transparent samples like solid $\mathrm{H}_{2}$ or polyethelene. Because in this case the unshocked part of the sample forms a transparent anvil. material on the principal Hugoniot can be observed directly for times as long as 1 ns. If the electrons and ion temperatures behind these strong shocks can equilibrate on such short time scales, the temperatures aln be meanured $u$ ith optical pyrometry. Because the electron-ion equilibration time for elastic scattering is $\left(M_{/ n} n\right)^{1}=($ inen the slectronion scattering time, where $M$ and $m$ are the ion and electron masses, respectively, and, because the electronion scattering ime is typicaliy $10^{-15} \mathrm{~s}$ or less for room-temperature normal-density metals, thermal equilibration may occur on sub-picosecond time scales. Nonequilibrium radiation, such as that asse wited with inelastic collisions of electrons with ions and subsequent line radiation, must, of course. be accounted for.

Line emission may also be used as a temperature indicator if the participating atomic tevels cun achieve local thermodynamic equilibrium (LTE) in the short time scales. For example. doping $\mathrm{H}_{2}$ with a small concentration of He could give rise to $587.5-\mathrm{nm}$ radiation from $\mathrm{Hel}$ and $468.6 \mathrm{-nm}$ radiation from Hell, which can be used for temperature determinations at 3 to $6 \mathrm{eV}$. Besides the LTE. assumption, problems associated with this measurement include the density dependence of oscillator strengths and Stark broadening. 


\section{REFERENCES}

1. R. I.. Kidder. lant Funion 8. 3 (1968).

2. (. Fauquignon and I, Floux. Thes Fhids 13. 386 (1970).

3. T. P. Hughs. Plawman and Laser Light (John Wiey \& Sons. New York. 1975).

4. (i. B. Zimmermitn and W. L. Krutr. Commert: Plasma Phys. 2. 51 (1975).

5. II. K. Mto and P. N. Bell. Sicrice 191.851 (976).

6. S. Block and (;. Piermarini. Plyss. Torlar. Seju. 1976. p. 44.

7. (j. R. (iathers. J. W. Shaner, and R. L. Brier. Rat. Sci. Instram. 47. 471 (1976).

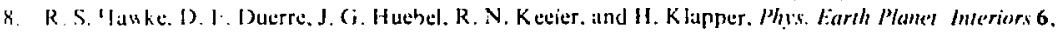
$4.4(1972)$.

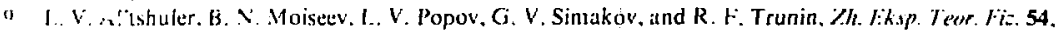
785 (1968) ISw Phy. .IF:TP 27. 420 (1968))].

10. (. R. Ragan III. M. G. Silbert. and B. C. Diven, I. Appl. Phys. 48. 2860 (1977).

11. I. V. al'tshuler. V. N. Kalitkin, L. V. Kuz'mina, and B. B. Chekin. Sov. Phls.-JE\%P 45. 167 (1977).

12. Cacer l'rugram fmmal Report-1975, Lawrence Livermọre Laboratory. Livermore. Calif., LCRL.$5(0) 21.75(1976)$.

1.3. K. R. .2lanes. V. C. P.upert, J. M. Auerbueh. P. Lee, and J. E. Swain, Phys. Rev. I.etr. 39.281 (1977).

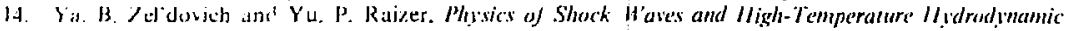
Phemmenta a Academic Press. New York. 1967). Ch. 7.

I5 Iater Irrigram tmmial Report-1974. Lawrence Livermore Laboratory, Livermore. Calif.. UCRI.5 (K) $21.74(1975)$. p. 292.

16. (. (; If ran Kerisel and R. Sigel. Phls. Rev. Leth. 33, 1020 (1974).

17. (. (i. wan Kesscl. Saurfarsch. 30a, 1581 (1975).

18. D. 1. Itlawod. J. H, Coleman. M. J. Boyle, J. T. Larsen. D. W. Phillion. and K. R. Manes, Mhs. Re't. l.in. 38. $282(1977)$.

19. A. V. Muerbath. D. S. Builey, S. S. Glaros. L. N. Koppel, Y. N. Pan, L. M. Richards, V. W. Slivinsky. J. J. Thomson. "Veon Spectral Line Broakdening As $\wedge$ Diagnostic For Compressed Lasti Fusion largets." I aurence livermore Laboratory, Livermore, Calif., UCRL-79636. Rev. I (1977).

20. M. V.al Thiel. "Compendium of Shock Wave Dala," Lawrence Livermore Laboratory. Livermore. (alif.. I:C R1-50108, Vol. 1-3, Rev. I (1977).

21. D. Billon. D. Cognard. J. I.aunspach, C. Patou, D. Redon, and D. Schirmann, Opt. Commun. 15. 108 $11975)$.

22. R. (irover. I an rence Livermore Laboratory, Livernore, Calif.. private communication (1978).

23. 1.. I . Wood. J. H. Vuckolls, und R. N. Keeler. "On The Generation of Very High Pressures for Physical

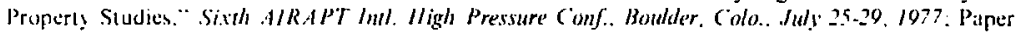
$M-5-\lambda$.

24. R. D. Cowan, "Thomas-Fermi-Dirac Equation of State." Los Alamos Scientific Laboratory, Los Nlamus. $>$. Mex.. I.A-2124 (1957).

25. H. Grabiske and 1 . Wong. The Eque'ion of Stare of Berylizm. Lawrence Livernore Laboratora, 1.iver-

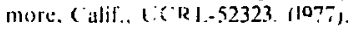

26. J. W. Taslor. I. t $1 \mathrm{ppl}$. Plys. 34, 2727 (1964).

27. P. J. King, D. F. (atgrave, and P. M. B. Slate, "Infrared Method of Estimating the Residual Tenperal ure of Shocked Metal Plates." in Behavior of Dense Media Lnder High Dinamis Pressure (Gordon \& Breach Science Pubs., New York. 1968).

28. P. A. I r riev. Phenomenological Survey of Experimemal Determination of Temperature of Shach-llated Salids, l.aw rence livernore Laboralory, Livermore, Calif., UCRI_-51432 (1973). 